\title{
Integrating infrastructures in the United States: experience and prospects
}

\author{
Thomas J. Wilbanks* \\ Oak Ridge National Laboratory
}

\begin{abstract}
Infrastructure integration has been limited in the United States because infrastructure management responsibilities are fragmented by divisions between sectors and between the public and the private sector, but some changes are under way. Stimulated by a number of extreme events in recent decades, data and modeling capabilities for simulating infrastructure interdependencies have been developed and applied, and infrastructure integration in some cities has been encouraged by such foci as emergency preparedness and "green infrastructure" strategies. Integrative strategies have been explored for energy and water resource systems, in some cases related to other sectors as well. In summary, infrastructure integration in the United States is occurring from the ground up, due in many cases to climate change impacts and risks. A number of examples of successes, supported by broad coalitions of interested parties (with evident sociopolitical payoffs), suggest that integration will increase through time. Key words: infrastructure integration, infrastructure interdependencies, infrastructure modeling and analysis, voluntary actions, nongovernmental roles.
\end{abstract}

Keywords: infrastructure; integration; silos; fragmentation; decision making.

\section{Introduction}

The need to view infrastructures as interconnected and interdependent has been widely recognized for years in the United States; but structural integration is problematic in a country where infrastructure management responsibilities are fragmented by divisions between the public and the private sector.

This paper first reviews the several decades of attention in the United States to interconnections. Second, it considers growing interest in exploring infrastructure integration as a strategy for enhancing resilience. Third, it notes several efforts to focus on an "energy-water nexus" in the United States, along with relationships with other sociotechnical systems including but not usually emphasizing transportation. It ends with some provisional conclusions about an integration process that is still evolving. 


\section{Understanding infrastructure interdependencies in responding to disruptive events}

Historically, infrastructure systems in the United States have been treated separately: separate ownership and accountability structures, separate management institutions, separate regulatory frameworks, research communities, literatures, and data bases. Most of the research and policy attention to concerns about effects of climate change was focused on sectors related directly to environmental conditions, such as ecology and hydrology. As systems engineered by humanity, often to reduce their sensitivity to environmental constraints, built infrastructures were usually viewed rather casually as a lower priority for attention to climate change vulnerability and risk assessment (e.g., Schelling, 1992).

An awareness of vulnerabilities of built infrastructures to "shocks" was raised during the oil embargos of the 1970s, but that threat - and the associated awareness - seemed to shrink with time. In the United States, the catalyst for a change in perspectives was the bombing of the World Trade Center in New York City on September 11, 2001. That catastrophe exposed widespread ignorance about interconnections between systems of all types in the U.S., and it led to a host of initiatives to improve the understanding and anticipation of vulnerabilities of urban areas, iconic buildings, and other infrastructures to terrorist events and other unpleasant disruptions.

One response was the creation of data and modeling foundations for analysis and forecasting, associated with National Infrastructure Analysis and Simulation Centers (NISAC) at the Los Alamos National Laboratory and the Sandia National Laboratories, supported by other national laboratories and also by uniquely detailed data bases under the auspices of the Homeland Security Partnership Program (HSIP), a collaboration between the Department of Homeland Security and the National Geospatial-Intelligence Agency. Since then, the array of tools has expanded, for example with the development by the Department of Energy of a Connected Infrastructure Dynamics Model (CIDM), featuring enhanced energy sector representations (see ORNL, 2012; Wilbanks, Fernandez et al., 2014; Wilbanks, Fernandez, and Allen, 2015).

This approach sees infrastructures as a "system of systems" (Figure 1). It represents 18 interconnected infrastructure layers, along with their subcomponents, and connects those subcomponents that are linked, such as traffic lights with electricity supply (Figure 2). 
Figure 1: ORNL, 2012

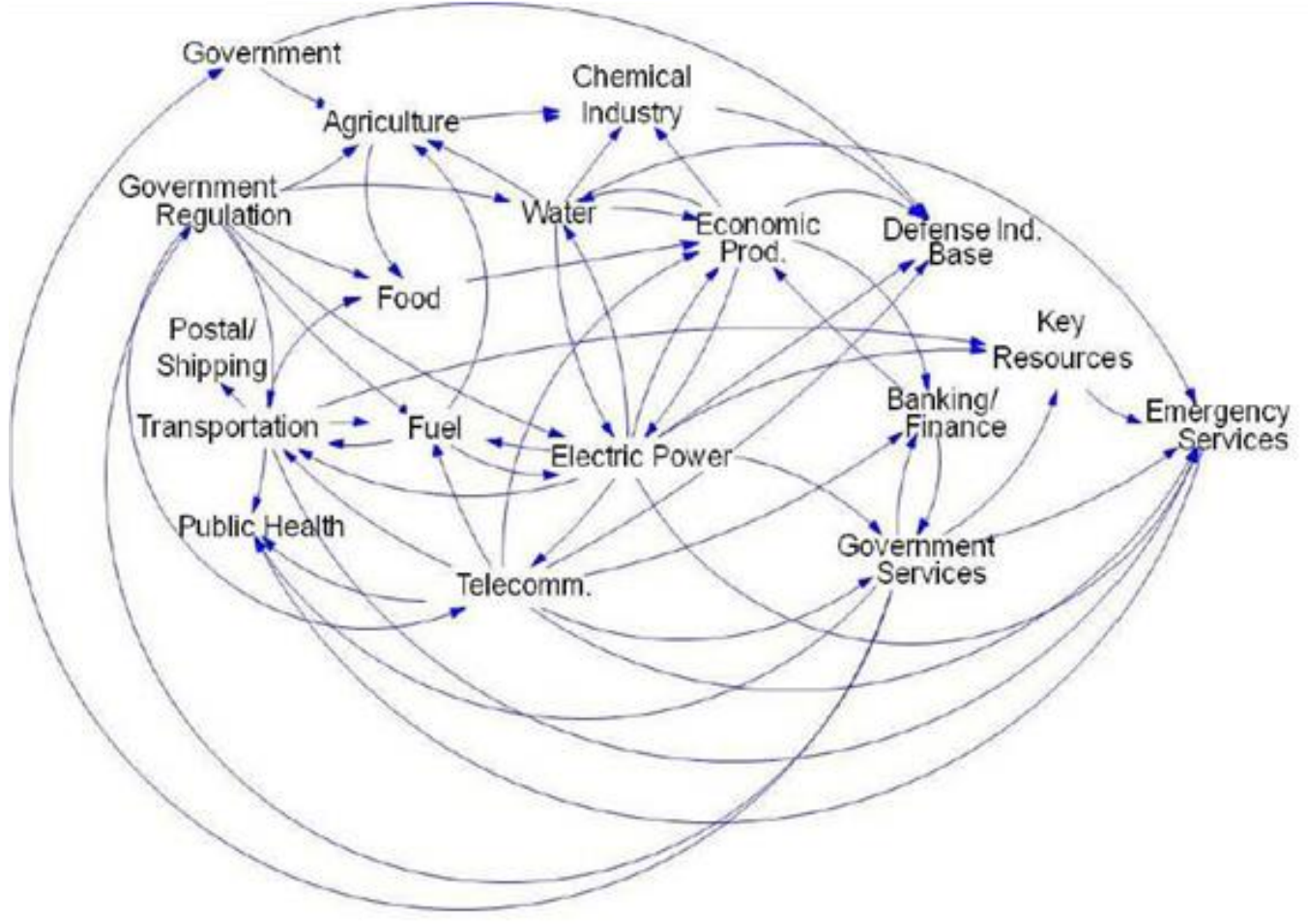

Figure 2: ORNL, 2012

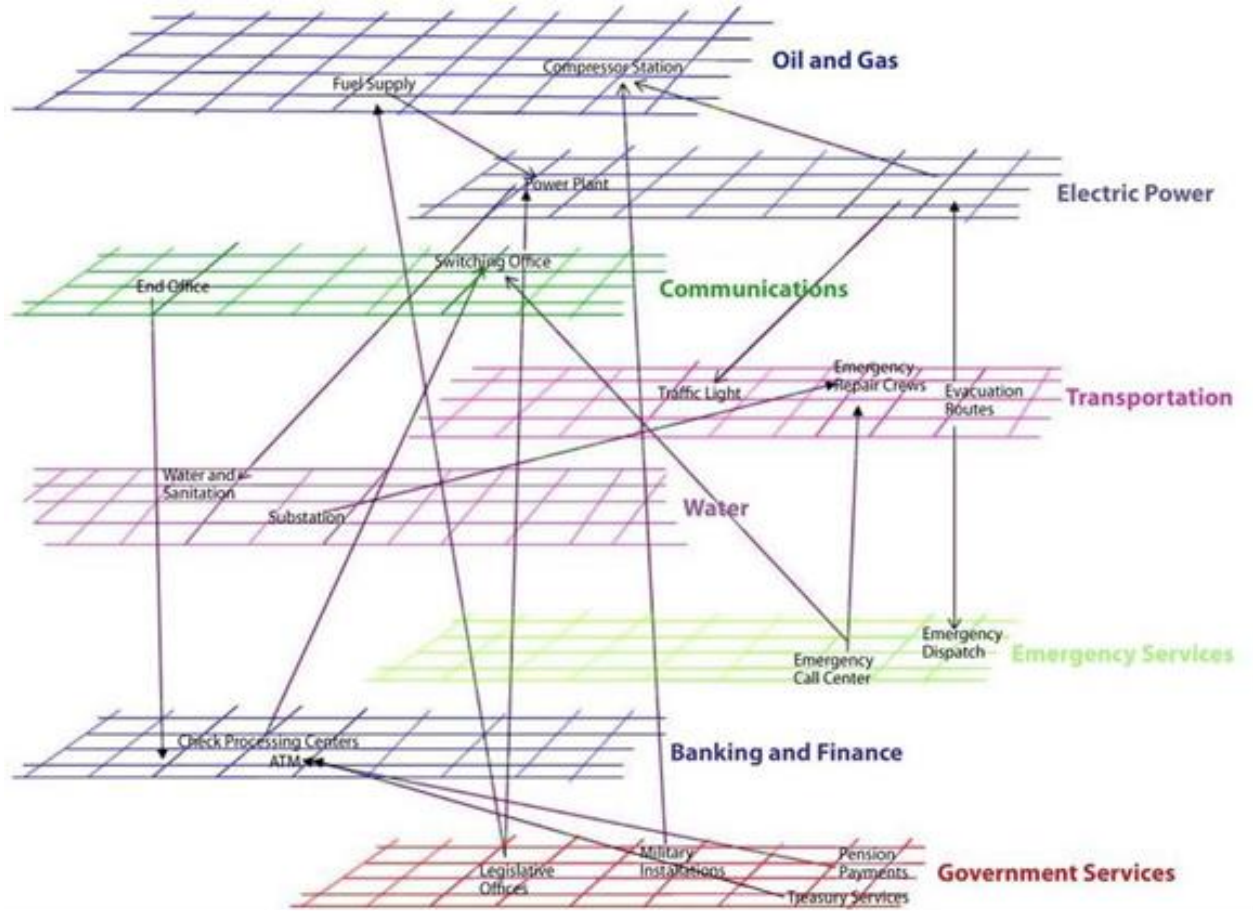

(c) 2017 The Author

People, Place and Policy (2017): 11/1, pp. 7-14

Journal Compilation @ 2017 PPP 
This capacity was designed primarily to meet national needs in anticipating and coping with disruptive terrorist acts, but over the following decades it was applied frequently to climate-related extreme weather events, especially major storms such as Hurricane Katrina in 1995 and "super-storms" Irene and Sandy more recently. In the wake of numerous disasters, NISAC and CIDM experts worked in real time with emergency responders, identifying emerging infrastructure problems and constraints and helping to track infrastructure recovery. After each case, the infrastructure modelers evaluated their tools to see where their projections were inaccurate or incomplete, and they have modified the tools accordingly - a remarkable opportunity to test and refine analytical models through real-world experience. For instance, based on such observations, they have been able to make summary judgments about the interdependencies among infrastructures that are most important (Figure 3).

Figure 3: Interdependencies among sectors in the event of major disruptive weather events (Wilbanks, 2014a)

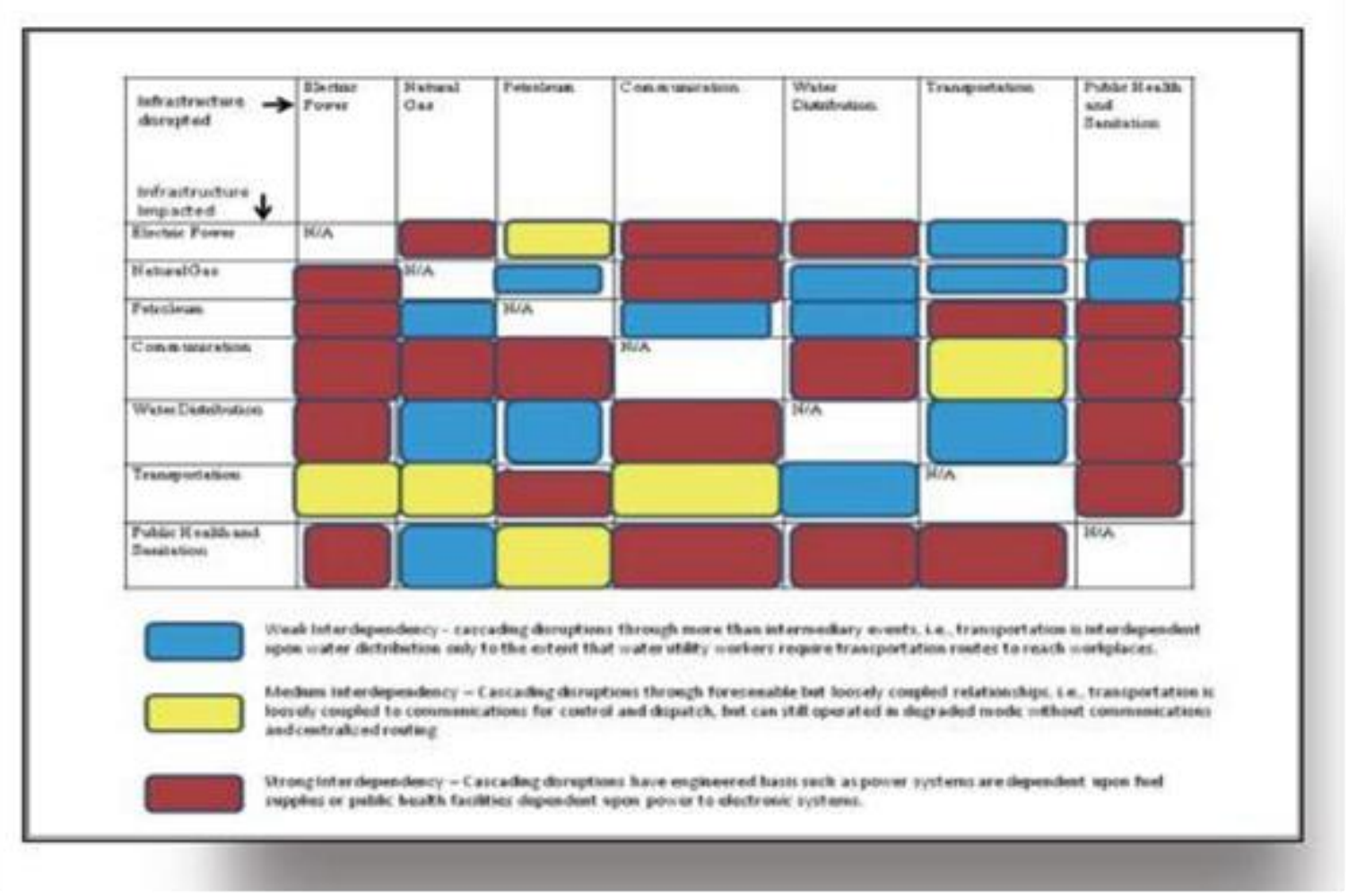

\section{Managing infrastructure interconnections to add resilience in anticipating disruptive trends and events}

Catastrophic events such as extreme storms, earthquakes, or terrorist acts drive attention to infrastructure integration through institutions for emergency response and recovery. Integration in order to anticipate disruptive conditions and take actions to reduce their severity, however, calls for structures that transcend emergency preparedness alone.

In the United States infrastructures vary profoundly in structural forms, responsible institutions, data sources, and the federal government agencies that provide support 
and oversight. For instance, Presidential Policy Directive 21, February 2013 (PDD21), identifies 16 infrastructure sectors (also see the Quadrennial Homeland Security Review: QHSR, 2014), and the infrastructure "report cards" of the American Society of Civil Engineers (ASCE) also identify 16 types, which are not identical to PDD21 sectors (ASCE, 2017). In their management, operation, and supporting research, infrastructures have tended to be treated individually; and structural interconnections are often poorly understood, even though they are known to be deeply and intricately interconnected (Wilbanks, Fernandez, et al., 2012; Kirshen, Ruth, and Anderson, 2008).

Most of the attention to infrastructure integration to date has been in an urban area context; in fact, the two topics are often combined (e.g., NCA, 2014b; Wilbanks, Fernandez, et al., 2014). Extensive literatures exist to illustrate infrastructure interactions in urban areas under climate-related extreme event stresses, along with adaptation strategies to reduce vulnerabilities in particular urban regions (e.g., City of New York, 2013; Boston, 2014; Chicago, 2008 and updates).

In fact, a considerable degree of coordination is required in urban areas because different infrastructures often share common space: e.g., (a) natural gas supply, water, and waste management underground, and (b) electricity, communications, and some forms of recreation dependent on delivery systems in the same general spaces aboveground.

Other focal points share this kind of pragmatic infrastructure integration because of a common focus on functions in shared space, such as ports and military facilities (e.g., Merad, Wilbanks, et al., 2014).

A catalyst for integrative infrastructure planning in some US cities has been initiatives to promote "green infrastructure" strategies: i.e., city-wide commitments to develop innovative, participative strategies that increase environmental sustainability, in some cases looking for synergies between climate change mitigation and climate change adaptation (Wilbanks, Fernandez, et al., 2014). Three leading examples are Philadelphia, New York, and Boston. Philadelphia is implementing a program to convert more than one-third of the city's impervious land cover to green streets, open spaces, buildings, and infrastructures in 25 years, funded in part by the development community as part of every new development project http://www.phillywatersheds.org/what were doing/green infrastructure). New York City has pursued a comprehensive, participative effort, PlaNYC, to increase the resilience of its built and natural environments and to protect its critical infrastructures from climate change and other risks (City of New York (2013)). Boston is pursuing an active climate change adaptation plan that includes integrated planning for infrastructures at risk (Boston, 2014). Other examples include Chicago (Chicago, 2008), Seattle, Portland, and Milwaukee. Such initiatives involve partnerships among public sector, private sector, and communities, often related to stormwater and wastewater management concerns.

But without a focal point such as an urban area, infrastructure integration in the US has no one in charge. The federal government talks about the nation's infrastructures in generic ways (e.g., the President's Climate Change Action Plan: Executive Office of the President, 2013), but in the US context it does not attempt to become the integrator. In most cases, integration is not something that the federal government does well, even within its own agencies; and it has other higher priorities. Where integrative perspectives exist, they tend to be in professional societies (such as ASCE, IEEE, and ASME), in non-governmental organizations, or the research community. 


\section{Attention to energy, water, and transportation infrastructure integration}

Meanwhile, integration is being pursued increasingly between a few infrastructure sectors, led by energy and water. Stimulated in part by the interest of New Mexico's former Senator Domenici, the idea of an "energy-water" nexus has been a continuing theme in the United States for several decades in the U.S. Congress, the U.S. Department of Energy, and the research community. Research opportunities and needs are summarized in DOE, 2014. More recently expanded to a broader concern about energy-water-"land" relationships (e.g., NCA, 2014a), the scope has been oriented toward resource systems, linked with the earth sciences, not toward physical infrastructures, linked with engineering perspectives. There is also growing interest in energy-water- food relationships, linked with research communities in Europe and the UK (e.g., the annual conference on Conference on Sustainable Development of Energy, Water and Environment Systems).

Much of this impetus in the U.S. is being driven by regional concerns about drought, raised by the experience of the south central US, especially Texas since 2013, and of the US southwest more recently, especially in California. Within the executive branch of the federal government, a high-level National Drought Resilience Partnership (NDRP) has been formed, to bring a national focus on drought resistance and resilience. This partnership includes development of a National Water Model, a project of a new multiinstitutional National Water Center that is being supported at the highest levels: e.g., a White House Water Summit on March 22, 2016.

One view in the United States has been that achieving a sustainable world over the next century will require technological change, not just technology applications (e.g., Wilbanks, 2011). At least in certain fields such as sustainable energy services, it seems clear that the enormous appetites for energy across the globe cannot be met without exceeding emission targets such as GHG stabilization at 2 degrees C or less without energy technology options that are not now available. Other such challenges include affordable desalination of seawater and effective and affordable waste management technologies for lower-income developing countries. Major technological change always has institutional implications, and such implications would add complexity to infrastructure integration as it evolves.

\section{Prospects for infrastructure integration in the US}

It seems most likely that infrastructure integration in the United States will increase in future years, very largely through bottom-up initiatives in particular cities and regions but related to policies at the federal government as well.

In general in the US, movements toward greater integration depend on a combination of incentives, which enhance mutual interest among the individual infrastructure sectors, and leadership in catalyzing commitments and action. History suggests that integration needs a focus, at least initially, such as a shared, visible commitment to green infrastructure or a shared responsibility for emergency preparedness. Meanwhile, integration is benefiting from the information and communication revolution, which stimulates and feeds a growing appetite for data about what is happening, shared across infrastructure communities and their constituencies and stakeholders. An excellent current example is the Center for Urban Science + Progress at New York University, a broad partnership which seeks to harness "big data" using exploding access to informatics capabilities and diverse categories of sensors, in a sense instrumenting its city to inform government and enable the private sector to develop new services (http://cusp.nyu.edu/urban-informatics/). As this kind 
of vision shapes governance and financing, probably pushed by an increasing frequency and severity of weather-related extreme events, infrastructure integration can be expected to evolve through partnerships rather than edicts.

In this sense, possible stimuli for integration will include a heightened awareness of interdependencies and shared risks (e.g., Wilbanks, 2014b) and the roles of nongovernmental parties in raising awareness and promoting integration: engineering societies such as ASCE, NGOs, educational institutions, and others. Possible mechanisms will include participatory city or regional resilience/sustainability planning, including joint participation in contingency planning to build awareness and also to build communication networks across infrastructures. Federal government funding for infrastructure enhancement can also play an important role, especially if it includes incentives for integration: e.g., integrating transportation infrastructure enhancement with strategies for future urban development.

In summary, infrastructure integration in the United States is occurring from the ground up, due in many cases to climate change impacts and risks. A number of examples of successes, supported by broad coalitions of interested parties (with evident sociopolitical payoffs), suggest that integration will increase through time. Prospects are encouraging that some forms of integration will become an element of progress business models in many individual sectors, drawing on an emerging body of experience with innovations elsewhere.

\section{Acknowledgments}

The author acknowledges programmatic support from the Integrated Assessment Research Program, Office of Science, U.S. Department of Energy.

* Correspondence address: Richard Dunning, Department of Geography and Planning, University of Liverpool. Email: r.j.dunning@liverpool.ac.uk / Nick Taylor Buck, Urban Institute, University of Sheffield. Email: n.taylor-buck@sheffield.ac.uk

\section{References}

ASCE (2017) ASCE's 2017 Infrastructure Report Card. Available at: http://www.infrastructurereportcard.org/ [Accessed: 25/07/2017]

Boston (2014) Greenovate Boston: Climate change action plan update. Available at: http://www.cityofboston.gov/eeos/pdfs/Greenovate\%20Boston\%202014\%20CA P\%20Up date Full.pdf

Chicago (2008) Chicago climate action plan update. Available at: http://www.cityofboston.gov/eeos/pdfs/Greenovate\%20Boston\%202014\%20CA P\%20Up date_Full.pdf

City of New York (2013) A stronger, more resilient New York - New York City Special Initiative for Rebuilding and Resilience. New York NY. Available at: http://www.nyc.gov/html/sirr/html/report/report.shtml

DOE (2014) Water-Energy Program Plan. Washington: US Department of Energy.

Executive Office of the President (2013) The President's Climate Change Action Plan. Washington.

Kirshen, P., Ruth, M. and Anderson, W. (2008) Interdependencies of urban climate change impacts and adaptation strategies: A case study of metropolitan Boston USA. Climatic Change, 86, 105-122. 
Merad M., Wilbanks T.J., Halfaoui L., Marcomini A., John C.S., Tkachuk A. (2014) Integrated Perspectives on Sustainable Infrastructures for Cities and Military Installations. In: Linkov I. (eds) Sustainable Cities and Military Installations. NATO Science for Peace and Security Series C: Environmental Security. Springer, Dordrecht

NCA (2014a) “Energy, Water, and Land Use," Climate Change Impacts in the United States, Chapter 10. US Global Change Research Program.

NCA (2014b) "Urban and Infrastructure," Climate Change Impacts in the United States, Chapter 11. US Global Change Research Program.

ORNL (2012) Climate Change and Infrastructure, Urban Systems, and Vulnerabilities. Technical Report to the U.S. Department of Energy in Support of the U.S. National Climate Assessment, February 2012.

QHSR (2014) Quadrennial homeland security review. Washington DC: Department of Homeland Security.

Schelling, T.C. (1992) Some economics of global warming. The American Economic Review, 82, 1.

Wilbanks, T. (2011) Inducing Transformational Energy Technological Change, In: W. Nordhaus and N. Nakicenovic (eds) Technological Change and Global Warming, special issue of Energy Economics, 33, 4, 699-708.

Wilbanks, T. (2014a) Implications of Climate Change for Energy Systems in a Multisectoral Context, In: J. Pittock et al. (eds) Climate, Energy and Water: Managing a Complex Trinity. Cambridge University Press.

Wilbanks, T. (2014b) Reflections on Enhancing Community and Infrastructure Resilience. Report for the Northeastern University Center for Resilience. Studies and the National Institute of Standards and Technology on Themes, Findings, and Recommendations Resulting from the International Resilience Symposium, September 3-4, 2014.

Wilbanks, T., Fernandez, S. et al. (2014) Climate Change and Infrastructure, Urban Systems, and Vulnerabilities. Island Press.

Wilbanks, T., Fernandez, S. and Allen, M. (2015) Meeting Challenges in Understanding Impacts of Extreme Weather Events on Connected Infrastructures. Environment, 57, July/August, 4-15.

Wilbanks, T., et al. (forthcoming) Toward Indicators of the Resilience of U.S. Infrastructures to Climate Change Risks, with others, In: A. Janetos and M. Kenney (ed) Special issue on "National Climate Indicators. Climatic Change, forthcoming 2016. 